Bulletin of Pharmaceutical Sciences
Assiut University
Website: http://bpsa.journals.ekb.eg/
e-mail: bullpharm@aun.edu.eg

\title{
ASSESSMENT OF KNOWLEDGE BELIEVES AND MYTHS REGARDING THE USE OF MASK IN COVID-19 OUTBREAK IN KARACHI PAKISTAN
}

\author{
Saira Shahnaz ${ }^{1 *}$, Mudassar Iqbal Arain ${ }^{2}$, Khurram, Anwar ${ }^{3}$ and Ramesha Anwar ${ }^{4}$ \\ ${ }^{1}$ Department of Pharmacy Practice, Faculty of Pharmacy, Ziauddin University, Karachi, \\ Pakistan \\ ${ }^{2}$ Department of Pharmacy Practice, Faculty of Pharmacy, University of Sindh Jamshoro, \\ Pakistan \\ ${ }^{3}$ Isra Dental College, Hyderabad, Pakistan \\ ${ }^{4}$ Faculty of Pharmacy, University of Sindh, Jamshoro, Pakistan
}

\begin{abstract}
Objective: To assess the general perspective of population their believes and myths regarding the pandemic outbreak and use of mask as precautionary measures.

Methods: A Cross-sectional observational study conducted from January-June 2020, among the general population of Karachi. Total 470 participant age range of $18-60$ years were included in the study. Data was analyzed by SPSS version 21.0, for descriptive statistics. Correlation between variables was assess by Kruskal Wallis Test, spearman rank correlation was established to assess the significant correlation between Knowledge, myths and practices.

Result: Out of 470 respondents, $74.31 \%$ were male and $25.69 \%$ of female. More than half of respondents aged between 51 to 70 years i.e. $53.92 \%$. While $21.76 \%$ respondents were categorized in illiterate category. The mean rank score for knowledge, myths and practices were $217.95 \pm 2.1$, myths score was $236.07 \pm 2.1,241.12 \pm 2.1$ respectively. The spearman rank correlation was established between knowledge myths and practices, a significant correlation between was established by Knowledge-myths $(r=0.0176, p=0.015)$, knowledge-practices ( $r=$ $0.0174, p=0.001)$ however myths-practices $(r=0.0170, p<0.001)$. Believes and myths related to the mask was concerned i.e. 56.1 were using $N$-95 masks, $89 \%$ respondents reused the masks, $59.1 \%$ used the mask between 2 to 5 times. Wearing mask is not a precautionary measure was mainly found as a myth in respondents i.e. 78.7\%. 67.2\% respondents had myths about unnecessary use of mask. The study highlighted the non-optimal behavior and practice with regards to the use of preventive measure including the use of mask in the pandemic outbreak.
\end{abstract}

\section{INTRODUCTION}

COVID-19 was first reported in Wuhan, China, in December 2019 ${ }^{1}$. On March 11, 2020, COVID-19 was declared as pandemic by World health organization (WHO) World Health $^{2}$, and by March 17, 2020, there were more than 200,000 confirmed cases and over 8000 reported deaths from COVID-19 worldwide $^{3 \& 4}$. Coronavirus (COVID-19) is an infectious disease that has become common pandemic worldwide recently in 2019 in a very short time. The infection has taken the $80 \%$ of countries of world in short time, created hardships and challenges ${ }^{5}$. COVID-19 has been decreed as deadly infection and speeded like wildfire in different nations. The coronaviruses are the group of related viruses which leads to infections/diseases in birds and mammals. The group can cause the respiratory tracts infections in humans and can be lethal illness and sometimes fetal. The mild illnesses include the symptoms like common cough and cold, predominantly like rhinoviruses, whereas the lethal infections can cause the MERS, SARS and COVID- $19^{6}$. The assessment of 
knowledge, and believes regarding the most recent pandemic is important to find, since the findings can be informative for public in this short time span, the response of people can vary from person to person. The COVID-19 epidemic has affected the population around the globe, and had strong impact on the behavior and practices of general populations. The major concern of general population is stay safe during the epidemic breakout, yet half of them misunderstood and became victim of myths and misleading thoughts ${ }^{7}$. The epidemic has greatly influenced the understanding and news of media, hence the misperceptions during the epidemic was observed most commonly $^{8}$. In the past reported studies, the general populations believe and perceptions has been reportedly affected by the pandemics, either influenza, SARS ${ }^{9}$. The pandemic out breaks has always been a condition that effects the daily life of general population hence proved to be a frightening condition. The assessment of populations' knowledge and perception is not an easy task in the quick prevailing outbreak of virus. The objective of study was to assess the myths and believe regarding the use of mask during pandemic outbreaks.

\section{MATERIALS AND METHODS}

A cross-sectional observational study was conducted for the period of 6 months starting from January- June 2020 among the general population of Karachi regarding the believes and myths of recent pandemic outbreak and use of mask as preventive measure. A total 470 questionnaires were filled from participants willing to participate in the study. Data was collected through convenient sampling technique on a self-structured questionnaire after obtaining consent from participants willing to participate in the study. Participants with age range of 18-60 years were included in the study. Respondents were requested to complete the questionnaire, and confidentiality of data was assured. Questionnaire was constructed based on required variables and validated before collection of data. Questionnaire was divided into 3 parts, Part-A included the demographic details of participants, Part-B to assess the knowledge and perception however part-C to assess the myths and practices of participants related to the masks. Data was analyzed by SPSS version 22.0, for descriptive statistics (Frequencies, mean, median standard deviation), the correlations between demographic and myths was assess by applying Kruskal Wallis Test. Spearman rank correlation was established at 95\% confidence interval to assess the significant correlation between Knowledge, myths and practices of respondents.

\section{RESULTS AND DISCUSSION}

\section{Results}

Out of total 470 respondents $74.3 \%$ ( $n=$ $349)$ were males, and $25.6 \%(n=121)$ were females, $31.2 \% \quad(n=146)$ were single and $68.8 \%(n=324)$ were married. Data was collected randomly and $13.1 \% \quad(n=61)$ respondents were $18-30$ years old, $32.9 \%(n=$ $155)$ were $31-50$ years old, $53.9 \% \quad(n=254)$ were 51-70 years old. To evaluate the respondent's knowledge regarding the pandemic education level was assessed as shown in table 1 . To assess the knowledge of participants questionnaire was constructed with different statements to which the correct knowledge was depicted by $56.7 \%(n=266)$, whereas $16 \%(n=75)$ did not know the correct answer, $54.1 \%(n=254)$ was given in response to mode of transmission for COVID-19, 39.4\% $(n=185)$ responded incorrectly whereas $6.5 \%$ $(n=30)$ did not know. The prevention of infection and knowledge was responded correctly by $51.6 \% \quad(n=242)$, responded incorrectly by $18.7 \%(n=88)$, whereas $29.7 \%$ $(n=139)$ did not know about it. the statement of "Wearing Face mask can prevent the chances of infections" was correctly responded by $45.9 \%(n=215)$, incorrectly by $17.2 \%(n=$ $81)$ however $16 \%(n=75)$ did not know the correct answer.

The 41.7\% ( $n=191)$ responded correctly to the purpose of metal strip in surgical mask by $41.7 \%$ ( $n=191)$, incorrectly by $29.3 \%$ ( $n=$ 137), comparison of cloth mask and surgical mask was responded correctly by $30.8 \%$ ( $n=$ $144)$, incorrectly by $45.8 \%(n=215)$, whereas $23.4 \%(n=109)$, as shown in table 2 .

To assess the believes and myths, believes regarding the use of mask was assess in the survey, the basic question was recommended mask by general populations, N-95 was 
suggested by $56.1 \%(n=263)$, surgical mask was recommended by $34.2 \%$ ( $n=161)$ whereas cloth mask was suggested by $34.2 \%(n=161)$.

$89 \%(n=418)$ respondents were wearing mask, whereas $11.3 \% \quad(n=53)$ respondents stated they repeats the use of mask 1-2 times, $59.1 \%(n=277) 2-5$ times, whereas $29.6 \%$ ( $n=$ 139). $67.2 \%(n=316)$ accepted the use of mask as myth and unnecessary, whereas $32.8 \%$ ( $n=$ 154) disagreed with the statement. $86.7 \%(n=$ 407) respondents agreed that only older patients should wear the mask/gloves, as shown in the table 3.
The practices of respondents were assessed regarding the use of mask, 27.2\% ( $n=$ 127) were wearing mask correctly, $12.8 \%$ ( $n=$ 60 ) were wearing mask with wrong side. $20.8 \%$ $(n=98)$ did not wear mask with the correct way. During the interview and data collection $14.2 \%(n=67)$ were observed for touching their mask, $12.3 \% \quad(n=58)$ were not feeling comfortable with masks. The practices of respondents with mask is represented in table 4 and figure 1.

Table 1: Demographic details of participants.

\begin{tabular}{|c|c|c|c|c|c|c|c|c|}
\hline \multicolumn{2}{|c|}{ Individualities } & $\mathrm{n}(\%)$ & $\begin{array}{c}\text { K-Score } \\
\text { Mean Rank } \\
217.95 \\
\pm 2.1 \\
\end{array}$ & $\begin{array}{c}\mathrm{p}- \\
\text { value }\end{array}$ & $\begin{array}{c}\text { M- Score } \\
\text { Mean rank } \\
236.07 \\
\pm 2.1 \\
\end{array}$ & $\begin{array}{c}p- \\
\text { value }\end{array}$ & $\begin{array}{c}p \text {-score } \\
241.12 \\
\pm 2.1\end{array}$ & $\begin{array}{c}p- \\
\text { value }\end{array}$ \\
\hline \multirow{2}{*}{ Gender } & Male & $\begin{array}{c}349 \\
(74.31 \%)\end{array}$ & 245.11 & \multirow{2}{*}{0.33} & 234.81 & \multirow{2}{*}{0.021} & 214.11 & \multirow{2}{*}{0.280} \\
\hline & Female & $\begin{array}{c}121 \\
(25.69 \%)\end{array}$ & 216.91 & & 255.23 & & 265.23 & \\
\hline \multirow{2}{*}{$\begin{array}{l}\text { Marital } \\
\text { Status }\end{array}$} & Single & $\begin{array}{c}146 \\
(31.2 \%)\end{array}$ & 234.34 & \multirow{2}{*}{0.00} & 233.78 & \multirow{2}{*}{0.001} & 233.81 & \multirow{2}{*}{0.161} \\
\hline & Married & $\begin{array}{c}324 \\
(68.8 \%)\end{array}$ & 216.34 & & 261.56 & & 265.45 & \\
\hline \multirow{3}{*}{ Age } & $18-30$ years & $\begin{array}{c}61 \\
(13.13 \%)\end{array}$ & 245.78 & \multirow{3}{*}{0.214} & 217.66 & \multirow{3}{*}{0.217} & 267.45 & \multirow{3}{*}{0.421} \\
\hline & $31-50$ years & $\begin{array}{c}155 \\
(32.94 \%)\end{array}$ & 231.87 & & 194.03 & & 214.67 & \\
\hline & 51-70years & $\begin{array}{c}254 \\
(53.92 \%)\end{array}$ & 278.67 & & 236.12 & & 211.34 & \\
\hline \multirow{4}{*}{ Literacy } & Illiterate & $\begin{array}{c}10 \\
(21.76 \%)\end{array}$ & 182.34 & \multirow{4}{*}{0.024} & 278.33 & \multirow{4}{*}{0.081} & 231.56 & \multirow{4}{*}{0.001} \\
\hline & Matriculation & $\begin{array}{c}169 \\
(35.9 \%) \\
\end{array}$ & 267.22 & & 213.56 & & 189.33 & \\
\hline & Intermediate & $\begin{array}{c}140 \\
(29.8 \%)\end{array}$ & 234.56 & & 234.45 & & 294.43 & \\
\hline & University & $\begin{array}{c}59 \\
(12.54 \%)\end{array}$ & 276.23 & & 237.34 & & 266.12 & \\
\hline
\end{tabular}

$p$-value of $<0.05$ was considered as significant; $\mathrm{K}$-Wallis $\mathrm{H}$ test, $\mathrm{K}$-Score $=$ average score of knowledge, $\mathrm{M}$-score $=$ Average score for myths, P-Score=average score of practices. 
Table 2: Knowledge and perception of respondents.

\begin{tabular}{||l|c|c|c||}
\hline Knowledge and perception of respondents & $\begin{array}{c}\text { Correct } \\
n(\%)\end{array}$ & $\begin{array}{c}\text { Incorrect } \\
n(\%)\end{array}$ & $\begin{array}{c}\text { Don't know } \\
n(\%)\end{array}$ \\
\hline $\begin{array}{l}\text { Most susceptible age group to COVID-19 } \\
\text { outbreak }\end{array}$ & $266(56.7 \%)^{*}$ & $128(27.1 \%)$ & $75(16 \%)$ \\
\hline $\begin{array}{l}\text { Mode of transmission for COVID-19 } \\
\text { infection }\end{array}$ & $\begin{array}{c}254 \\
(54.1 \%)^{* *}\end{array}$ & $185(39.4 \%)^{*}$ & $30(6.5 \%)^{* *}$ \\
\hline $\begin{array}{l}\text { The infection can be Prevented by } \\
\text { precautions }\end{array}$ & $242(51.6 \%)$ & $88(18.7 \%)$ & $139(29.7 \%)$ \\
\hline $\begin{array}{l}\text { Wearing Face mask can prevent the } \\
\text { chances of infections }\end{array}$ & $215(45.9 \%)$ & $179(38.1 \%)^{*}$ & $75(16 \%) *$ \\
\hline $\begin{array}{l}\text { Personal hygiene/Hands washing is } \\
\text { important factor in prevention }\end{array}$ & $246(52.5 \%) *$ & $81(17.2)^{*}$ & $142(30.3 \%)$ \\
\hline $\begin{array}{l}\text { What is purpose of metal strip on surgical } \\
\text { mask }\end{array}$ & $191(41.7 \%)$ & $137(29.3 \%)^{*}$ & $\begin{array}{c}136 \\
(29 \%)^{* *}\end{array}$ \\
\hline Cloth mask is as effective as surgical/other & $144(30.8 \%)$ & $215(45.8 \%)$ & $109(23.4 \%)$ \\
\hline
\end{tabular}

$* p$ value $=0.001, * * p=<0.05$

Table 3: Believes and myths related to mask.

\begin{tabular}{|c|c|c|c|}
\hline \multicolumn{2}{|c|}{ Variables to assess the Believes of participants } & $n(\%)$ & $p$-values \\
\hline \multirow{3}{*}{$\begin{array}{l}\text { Which mask is recommended (according to } \\
\text { respondents) }\end{array}$} & $\mathrm{N}-95$ & $263(56.1 \%)$ & \multirow{3}{*}{0.00} \\
\hline & Surgical mask & $161(34.2)$ & \\
\hline & Cloth mask & $46(9.7 \%)$ & \\
\hline \multirow{2}{*}{ Do you reuse the mask } & Yes & $418(89 \%)$ & \multirow{2}{*}{0.028} \\
\hline & No & $51(11 \%)$ & \\
\hline \multirow{3}{*}{ How often you reuse the mask } & $1-2$ times & $53(11.3 \%)$ & \multirow{3}{*}{0.045} \\
\hline & $2-5$ times & $277(59.1 \%)$ & \\
\hline & 6-10 times & $139(29.6 \%)$ & \\
\hline \multirow{2}{*}{ Wearing mask is preventing me to get infected } & Yes & $101(21.3 \%)$ & \multirow{2}{*}{0.001} \\
\hline & No & $369(78.7 \%)$ & \\
\hline \multirow{2}{*}{ Use of mask is unnecessary/It's a myth } & Yes & $316(67.2 \%)$ & \multirow{2}{*}{0.022} \\
\hline & No & $154(32.8 \%)$ & \\
\hline \multirow{2}{*}{$\begin{array}{l}\text { Mask has nothing to do with } \\
\text { infection/wearing mask doesn't matter }\end{array}$} & Yes & $305(64.9 \%)$ & \multirow{2}{*}{0.298} \\
\hline & No & $165(35.1 \%)$ & \\
\hline \multirow{2}{*}{$\begin{array}{l}\text { Older patients should be advice for } \\
\text { mask/gloves }\end{array}$} & Yes & $407(86.7 \%)$ & \multirow{2}{*}{0.067} \\
\hline & No & $63(13.3 \%)$ & \\
\hline
\end{tabular}

Table 4: Practices of respondents regarding the mask.

\begin{tabular}{|c|c|c|}
\hline \multicolumn{2}{|c|}{ Practices of respondents with respect to Mask } & $n(\%)$ \\
\hline \multirow{7}{*}{$\begin{array}{c}\text { Respondents } \\
\text { Practices with mask }\end{array}$} & Wearing mask correctly & $127(27.2 \%)^{* *}$ \\
\hline & Wearing mask with facing wrong side on & $60(12.8 \%)$ \\
\hline & Not covering Nose, Mouth/Chin & $98(20.8 \%)^{*}$ \\
\hline & Not fixed properly & $21(4.4 \%)$ \\
\hline & Removed mask while talking & $39(8.3 \%)$ \\
\hline & Touching/setting mask & $67(14.2 \%)^{*}$ \\
\hline & Not feeling comfortable while wearing & $58(12.3 \%)$ \\
\hline
\end{tabular}

$* p$ value $<0.005, * *<0.001$ 


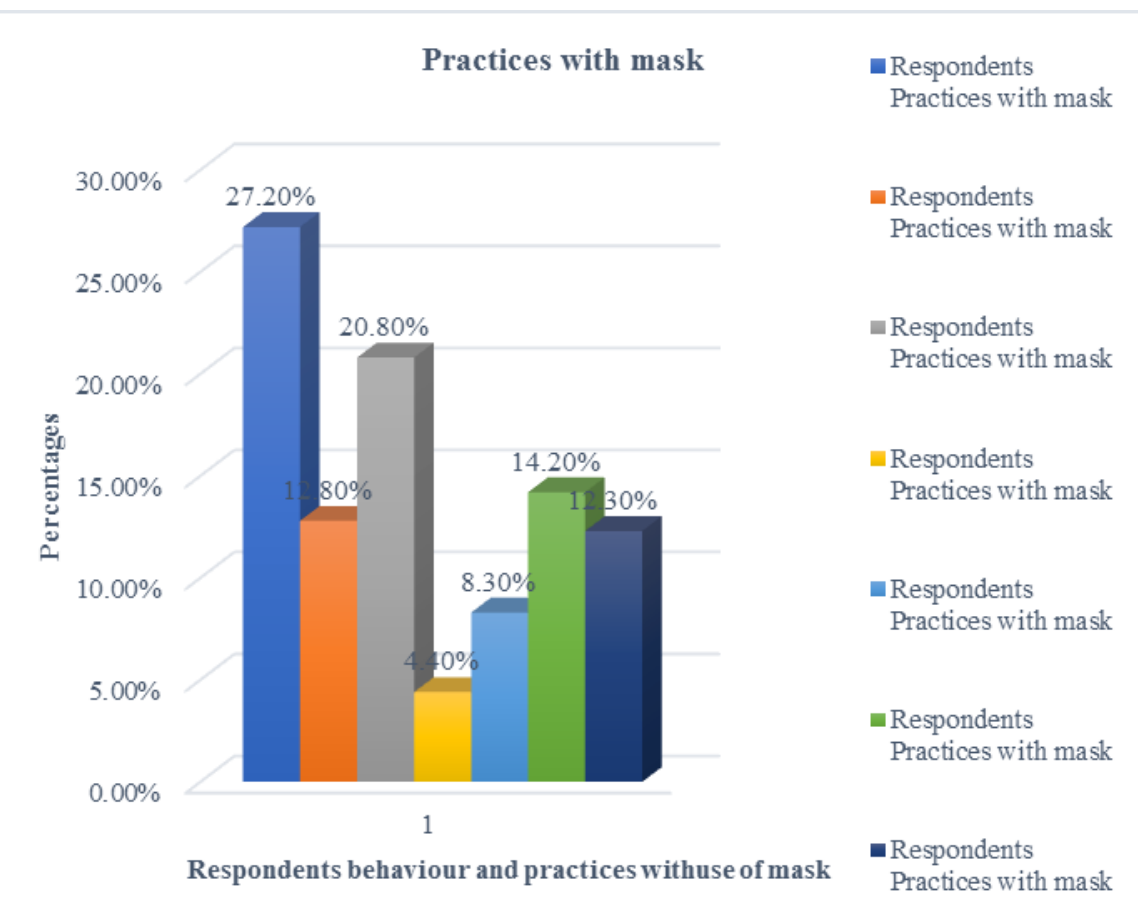

Fig. 1: Respondents behaviour and practices withuse of mask.

Correlation between knowledge, myths and the practices of respondents.

\begin{tabular}{||l|c|c||}
\hline \multicolumn{1}{|c|}{ Variables } & Rho & $p$-values \\
\hline Knowledge + Myths & 0.0176 & 0.015 \\
\hline $\begin{array}{l}\text { Knowledge + } \\
\text { Practices }\end{array}$ & 0.0174 & 0.001 \\
\hline Myths + Practices & 0.0170 & $<0.001$ \\
\hline
\end{tabular}

\section{Discussion}

The pandemic serious out break happened in the end of year 2019. To which the preventive measures were addressed by WHO to avoid uncontrolled infection outbreak ${ }^{10}$. However the general population had different reviews on it. to assess the knowledge, believes and practices of population. Data was collected from general population, out of 470 respondent's majority $74.3 \%$ were males, however $31.2 \%$ were female, due to the situation $^{11 \& 12}$. Data was collected randomly and without the gender and age boundaries, $13.1 \%$ respondents were $18-30$ years old, since the questionnaires were distributed to the 18 years and above, $32.9 \%$ were $31-50$ years old in a similar study. mode of transmission for COVID-19 was $39.4 \%(n=185)$ responded incorrectly whereas $6.5 \% \quad(n=30)$ did not know $^{13}$. The prevention of infection and knowledge was responded correctly by $51.6 \%$ $(n=242)$, responded incorrectly by $18.7 \%(n=$ $88)$, whereas $29.7 \%(n=139)$ did not know about it. The use of mask is an important preventive barrier to reduce the risk of transmission of microorganism ${ }^{14}$. $56.1 \%$ suggested the correct mask, had enough knowledge, $67.2 \%$ considered the use of mask as myth ${ }^{15}$, and $64.9 \%$ did not believe in use of mask as preventive measure. The correlation was assessed in knowledge myths and their practices in use of mask ${ }^{16}$, highest value was obtained knowledge and myths, rho $=0.0176$, the significant relationship was obtained for the knowledge and false practices in use of $\operatorname{mask}^{17 \& 18}$, since the pandemic was taken as myth and wearing mask was not considered important 


\section{Conclusion}

The current outbreak of Covid-19 has given rise to development of various other risk factors, importantly the myths and believes regarding preventive measures had potentially affected the general population. The preventive measure has a strong influence on the pandemic situation, since the myths about curative and preventive measures are making the community over-complacent which resultantly leads to worsen the disease transmission. The uncertainty and insufficient knowledge of infection have cultural influence on the society can give rise to the potential risks. Considering the COVID-19 pandemic outbreak status, all possible and prompt steps should be taken and people should be guided to follow the precautionary measures. The appropriate authorities are directed to demystify the false believes and myths in due time.

\section{REFERENCES}

1- H. A. Rothan and S. N. Byrareddy, "The epidemiology and pathogenesis of coronavirus disease (COVID-19) outbreak", Journal of Autoimmunity, 109, 102433 (2020).

2- M. Chinazzi, J. T. Davis, M. Ajelli, C. Gioannini, M. Litvinova, S. Merler and C. Viboud, "The effect of travel restrictions on the spread of the 2019 novel coronavirus (COVID-19) outbreak", Science, 368 (6489), 395-400 (2020).

3- A. Wilder-Smith, C. J. Chiew and V. J. Lee, "Can we contain the COVID-19 outbreak with the same measures as for SARS?", The Lancet Infectious Diseases, 20 (5), E102-E107 (2020).

4- A. Aminian, S. Safari, A. RazeghianJahromi, M. Ghorbani and C. P. Delaney, "COVID-19 outbreak and surgical practice: Unexpected fatality in perioperative period", Annals of Surgery, 272 (1), e27-e29 (2020).

5- B. L. Zhong, W. Luo, H. M. Li, Q. Q. Zhang, X. G. Liu, W. T. Li and Y. Li, "Knowledge, attitudes, and practices towards COVID-19 among Chinese residents during the rapid rise period of the COVID-19 outbreak: A quick online cross-sectional survey", International
Journal of Biological Sciences, 16 (10), 1745 (2020).

6- E. Hager, I. A. Odetokun, O. Bolarinwa, A. Zainab, O. Okechukwu and A. I. AlMustapha, "Knowledge, attitude, and perceptions towards the 2019 Coronavirus Pandemic: A bi-national survey in Africa", PLoS ONE, 15 (7), e0236918 (2020).

7- R. C. Reuben, M. M. Danladi, D. A. Saleh and P. E. Ejembi, "Knowledge, attitudes and practices towards COVID-19: An epidemiological survey in north-central Nigeria", Journal of Community Health, 7, 1-14 (2020).

8- J. Lu, J. Gu, K. Li, C. Xu, W. Su, Z. Lai and Z. Yang, "COVID-19 outbreak associated with air conditioning in restaurant, Guangzhou, China, Emerging Infectious Diseases, 26 (7), 1628 (2020).

9- L. L. Lau, N. Hung, D. J. Go, J. Ferma, M. Choi, W. Dodd and X. Wei, "Knowledge, attitudes and practices of COVID-19 among income-poor households in the Philippines: A cross-sectional study", Journal of Global Health, 10 (1) (2020).

10- E. Morgul, A. Bener, M. Atak, S. Akyel, S. Aktaş, D. Bhugra and T. R. Jordan, "COVID-19 pandemic and psychological fatigue in Turkey", International Journal of Social Psychiatry, 0020764020941889 (2020).

11- M. Z. Ferdous, M. S. Islam, M. T. Sikder, A. S. M. Mosaddek and J. A. ZegarraValdivia, "Knowledge, attitude, and practice regarding COVID-19 outbreak in Bangladeshi people: An online-based cross-sectional study", MedRxiv, doi:https://doi.org/10.1101/2020.05.26.20 105700 , preprint (2020).

12- D. Bekele, T. Tolossa, R. Tsegaye and W. Teshome, "The knowledge and practice towards COVID-19 pandemic prevention among residents of Ethiopia. An online cross-sectional study", BioRxiv, doi:https://doi.org/10.1101/2020.06.01.12 7381, preprint (2020).

13- A. A. Azlan, M. R. Hamzah, T. J. Sern, S. H. Ayub and E. Mohamad, "Public knowledge, attitudes and practices towards COVID-19: A cross-sectional study in Malaysia", PLoS ONE, 15 (5), e0233668 (2020). 
14- A. W. Tadesse, N. Melese, S. Eshetie, M. Chane and A. Ali, "Knowledge, attitude, and practice and associated factors towards COVID-19 among college students in Amhara Region, Ethiopia, A cross-sectional study", Preprint (2020).

15- C. Y. Chin and C. L. Wang, "Effectiveness of COVID-19 pandemic prevention: A cross-country comparison of digital footprint of google search data", Advances in Management and Applied Economics, 10 (4), 23-34 (2020).

16- Y. Ren, Y. Zhou, W. Qian, X. Zhang, Z. Liu, R. Wang and Z. Li, Letter to the Editor "A longitudinal study on the mental health of general population during the COVID-19 epidemic in China", Brain,
Behavior, and Immunity, 87, 132-133 (2020).

17- G. Sharifirad, P. Yarmohammadi, S. M. A. Morowati and Z. Rahayi, "The status of preventive behaviors regarding influenza (A) H1N1 pandemic based on protection motivation theory among female high school students in Isfahan, Iran", Health System Research, 7 (1), 108-117 (2011).

18- N. D. Jhummon-Mahadnac, J. Knott and C. Marshall, "A cross-sectional study of pandemic influenza health literacy and the effect of a public health campaign", $\boldsymbol{B M C}$ Research Notes, 5 (1), 377 (2012). 


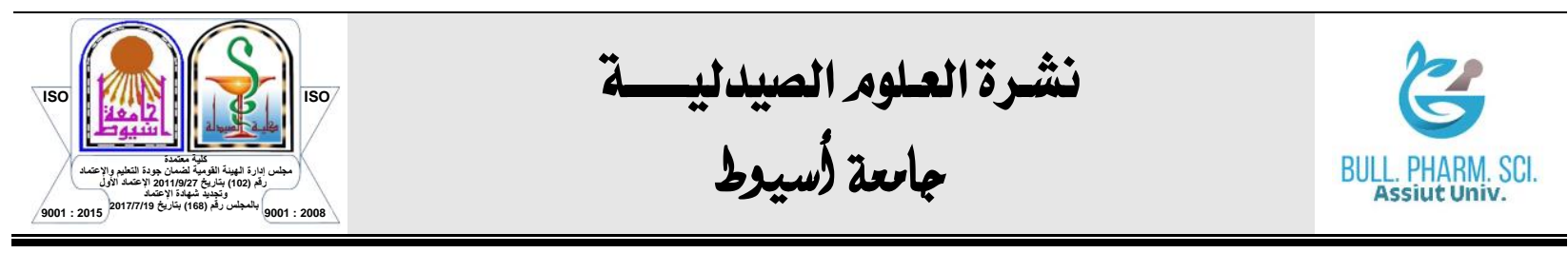

\section{تقييم المعتقدات المعرفية والأساطير المتعلقة باستخدام الكمامة في تفشي COVID-19}

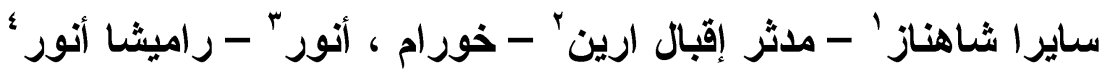

' قسم الممارسة الصيدلية ، كلية الصيدلة ، جامعة ضياء الدين ، كراتشي ، باكستان

'قسم الممارسة الصيدلية ، كلية الصيدلة ، جامعة السند ، جامشورو ، باكستان

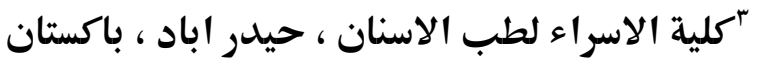

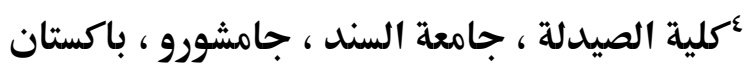

الهدف: نقييم المنظور العام للسكان ومعتقداتهم و أساطير هم فيما يتعلق بتفشي الوباء و استخدام الكمامسـات

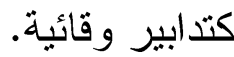

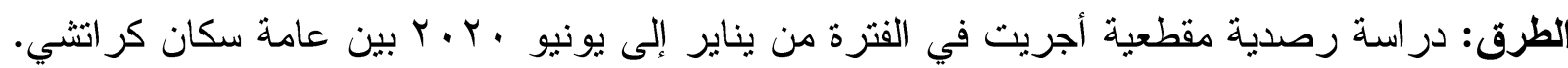

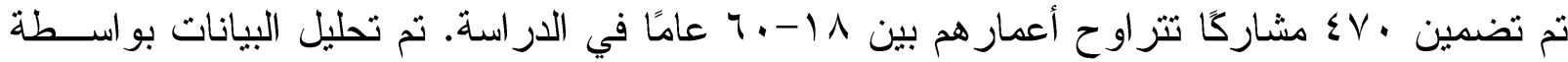
SPSS

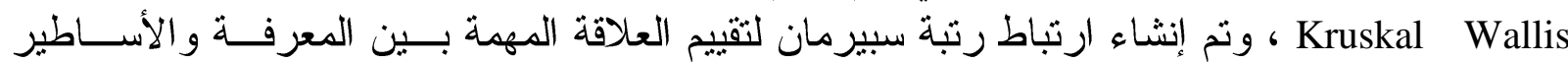

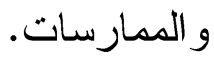

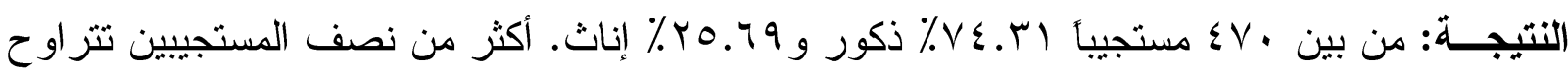

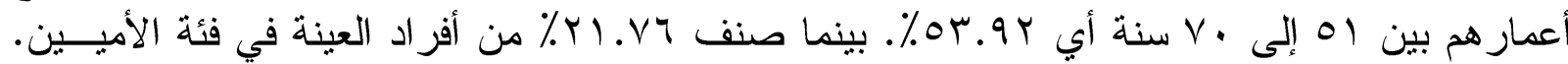

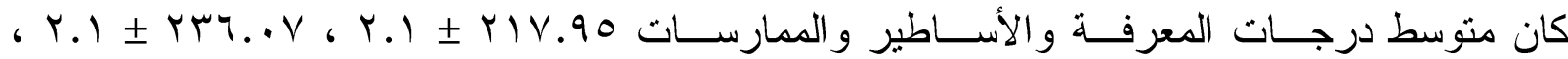

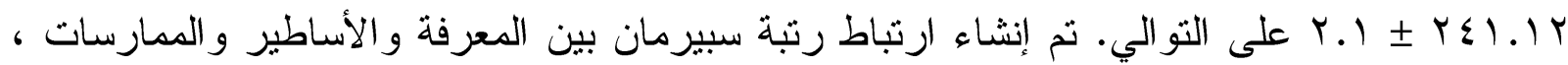

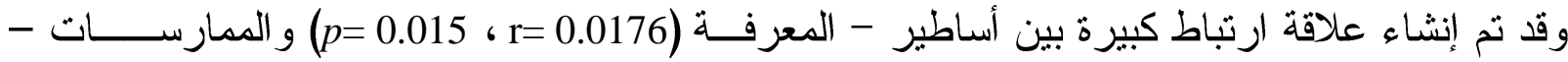

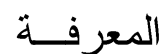

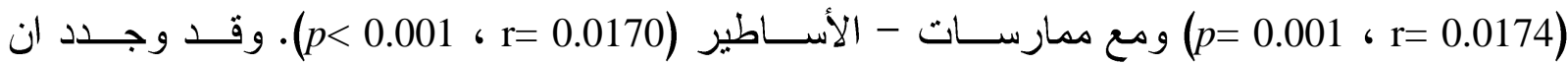

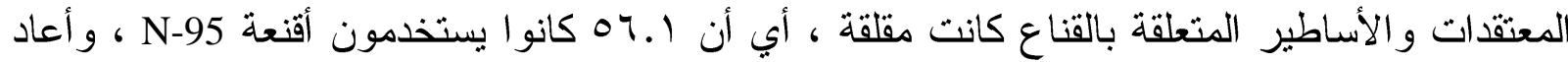

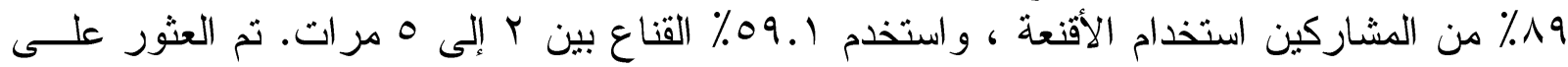

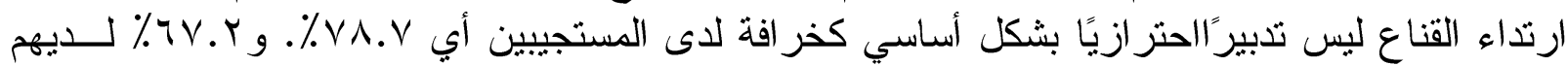

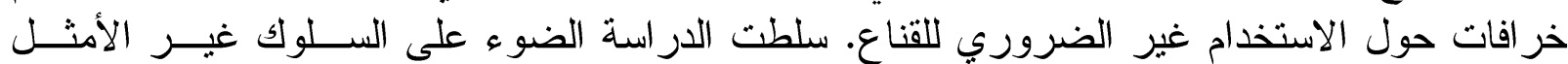

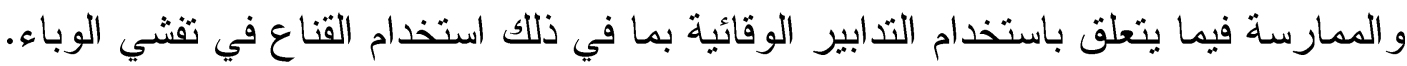

